\title{
Cooperativismo y justicia social para el posconflicto: una integración desde la economía solidaria para la generación de espacios de paz desde las regiones
}

\author{
Teddy Doria-Orozco $\square^{1}$
}

${ }^{1}$ Universidad Cooperativa de Colombia, Montería, Colombia

\author{
$\triangle$ tedys.doria@campusucc.edu.co \\ Recibido: 22 de febrero del 2017 Aprobado: 18 de julio del $2017 \quad$ Disponible en línea: 14 de enero del 2018 \\ Cómo citar este artículo: Doria-Orozco, T. (2018). Cooperativismo y justicia social para el posconflicto: una integración desde \\ la economía solidaria para la generación de espacios de paz desde las regiones. Cooperativismo \& Desarrollo, 112(25), 93- \\ 108. doi: https://doi.org/10.16925/co.v25i112.2039
}

\section{Resumen}

Propósito: se busca dar respuesta a las preguntas: ¿cómo el cooperativismo y la justicia social pueden hacer parte del posconflicto?, y ¿cómo la integración desde la economía solidaria sirve para la generación de espacios de paz desde las regiones?

Descripción: a fin de dar respuesta al presente interrogante se realiza un breve abordaje histórico del cooperativismo en Colombia y se analiza el desarrollo de la economía solidaria en Colombia con un enfoque de posconflicto y la generación de espacios de paz desde las regiones.

Punto de vista: en el proceso de construcción de una paz estable y duradera desde las regiones es necesario revisar las ventajas del cooperativismo y la justicia social, dado que permite fortalecer la trama social a través de la consolidación de experiencias con la práctica de los valores y los principios del sector solidario, lo cual da la pauta en la integración de las regiones y es el sustrato ejemplarizante que responde con la reinserción social, la reconciliación y el progreso de aquellos que más lo necesitan.

Conclusiones: se concluye que las buenas prácticas de los valores y los principios del sector solidario marcan un punto de referencia en la integración de las regiones, así como contribuyen a la reinserción social, la reconciliación y el progreso social.

Palabras clave: construcción de paz, cooperativismo, desarrollo territorial, economía solidaria, posconflicto. 


\title{
Cooperativism and Social Justice for the Post-conflict: Integration from the Solidarity Economy for the Generation of Peace Territories Starting from the Regions
}

\begin{abstract}
Purpose: The present paper seeks to answer the questions: how can cooperativism and social justice be part of Colombia's post-conflict situation? And how may integration from the solidarity economy help to create peace territories starting from the regions?

Description: A brief historical approach to cooperativism in Colombia is carried out to analyze the development of solidarity economy in the country pointing to a post-conflict situation and to the generation of peace territories starting from the regions.

Point of view: In the process of building a stable and lasting peace starting from the regions, it is necessary to contemplate the advantages of cooperativism and social justice, since they allow strengthening the social fabric through the consolidation of experiences with the practice of values and principles of the solidarity sector. These offer a pattern for the regional integration, thus becoming the exemplary substratum that responds to the social reintegration, reconciliation and progress of those who need it most.

Conclusions: The proper implementation of the values and principles of the solidarity sector mark a point of reference for regional integration, contribute to social reintegration, reconciliation and social progress.
\end{abstract}

Keywords: peacebuilding, cooperativism, territorial development, solidarity economy, postconflict.

\section{Cooperativismo e justiça social para o pós-conflito: uma integração a partir da economia solidária para a geração de espaços de paz a partir das regiões}

\section{Resumo}

Propósito: busca-se responder como o cooperativismo e a justiça social podem fazer parte do pósconflito e como a integração a partir da economia solidária serve para gerar espaços de paz a partir das regiões.

Descrição: realiza-se uma breve abordagem histórica do cooperativismo na Colômbia, a partir da qual é analisado o desenvolvimento da economia solidária no país visando o pós-conflito e a geração de espaços de paz a partir das regiões.

Ponto de vista: é necessário contemplar vantagens do cooperativismo e da justiça social no processo de construção de uma paz estável e duradoura a partir das regiões, visto que permitem fortalecer a trama social através da consolidação de experiências com a prática dos valores e dos princípios do setor solidário, já que eles oferecem uma pauta para a integração das regiões, constituindo-se, dessa forma, como a base exemplar que responde à reinserção social, à reconciliação e ao progresso daqueles que mais necessitam.

Conclusões: as boas práticas dos valores e princípios do setor solidário marcam um ponto de referência para a integração das regiões e contribuem para a reinserção social, a reconciliação e o progresso social.

Palavras-chave: construção de paz, cooperativismo, desenvolvimento territorial, economia solidária, pós-conflito. 


\section{Introducción}

Desde hace ya casi seis décadas, el conflicto en Colombia se ha acentuado de manera tal que ha generado desigualdad y retroceso en algunos espacios, y ha contribuido al aumento de las brechas sociales. Hoy existe una oportunidad para el fortalecimiento de la trama social con el fin de dar una mirada distinta a lo que no se encuentra ajustado en conformidad con lo que se denomina "progreso regional". La firma de los acuerdos de paz en Colombia el pasado 26 de septiembre del 2016 representó un paso en la generación de espacios de consolidación de paz para las regiones, y es entonces cuando la economía solidaria, el cooperativismo y la justicia social proporcionan las pautas para la estructuración de un verdadero desarrollo. En el presente artículo se revisan las ventajas sobresalientes del cooperativismo y la justicia social en la construcción de paz ${ }^{1}$ en el posconflicto, ${ }^{2}$ y se realiza una prospectiva de porqué la integración de estos dos elementos importantes son fundamentales para la generación de espacios de paz desde las regiones, al aterrizar la idea principal de la economía solidaria en Colombia, desde sus inicio, su fortalecimiento y el enfoque de transformación que esta plantea para el nuevo escenario de construcción social, construcción de paz y reintegración a la vida civil de guerrilleros, y el logro de la reconciliación a través del cooperativismo.

De esta manera, se aborda el ejemplo del avance del cooperativismo mundial ante estas situaciones similares como la que se presentará en Colombia con la entrada de un contexto de posconflicto. De

Conceptuado por la Universidad del Rosario (2014) como el "fortalecimiento y la solidificación de la paz para evitar una recaída en el conflicto. Es un concepto inferior en extensión a 'postconflicto' y abarca un mayor número de atributos, tales como el DDR (procesos de desarme, desmovilización y reintegración de excombatientes), la reconciliación, la atención a población vulnerable, la construcción de memoria y verdad, la justicia transicional y la reparación, la prevención de la violencia y el crimen, la reforma de las Fuerzas Armadas y de Policía, la reconstrucción y el desarrollo económico, la estabilización política y la participación del sector privado, la sociedad civil y la comunidad internacional en todos ellos". Véase también Galtung (1975), Boutros (1992), Chetail (2009) y Rettberg (2003; 2012).

2 Como señala la Universidad del Rosario (2014), el posconflicto es "el periodo de tiempo que sigue a la superación total o parcial de los conflictos armados. Puede entenderse como un concepto de un único atributo: la reducción del número de homicidios relacionados con el conflicto por debajo de un umbral determinado, que le otorga o le niega el estatus de conflicto activo". ahí el análisis que debe hacerse de cada experiencia exitosa y los procesos de consolidación social a través de la economía solidaria al revisar cómo se construyó la justicia social, y cómo prosperan el campo, los territorios, las regiones y las naciones después de un escenario de guerra y conflicto. Por esto, se toma como punto de análisis el caso de España, país que en la vivencia social atravesó por situaciones similares de cara al cooperativismo de la época, así como su contribución a la reconciliación y la construcción de un nuevo punto de partida hacia el desarrollo económico.

A fin de cumplir esta meta, también se debe fortalecer el emprendimiento solidario y fomentar la asociatividad, ya que el microempresario solidario es quien puede facilitar la construcción de un mejor tejido social en el escenario del posconflicto colombiano, e incorporar así a muchas personas a la vida laboral. Sin embargo, esta tarea no se puede llevar a cabo con esfuerzos aislados de emprendedores individuales, sino que se debe fomentar la asociatividad como base del capital social.

Según las estadísticas, la pobreza extrema en Colombia oscila en un $12,5 \%$, es decir, esta cifra representa alrededor de 5,5 millones de colombianos. Ahora bien, en el 2015, un hogar que está compuesto por cuatro personas fue clasificado así en razón a si el ingreso total del hogar estuvo por debajo de COP 894 552. El DANE (2016, p. 22) destaca que la desigualdad de género en la pobreza en el 2015 se encuentra representada por un $31,0 \%$, de modo que este porcentaje representa a aquellas personas que pertenecen a un hogar cuya jefatura era femenina; mientras que el 26,3\% de las personas en hogares con jefatura masculina. Con relación a los indicadores de pobreza monetaria y multidimensional en Colombia, según el DANE, este Índice de Pobreza Multidimensional (IPM) se construye con base en diferentes dimensiones, de las cuales hacen parte: condiciones educativas, de la niñez, la salud, el trabajo, acceso a servicios públicos y condiciones de vivienda.

Para 2015, el DANE (2016, p. 22) señala que el porcentaje de personas en situación de pobreza multidimensional fue de 20,2 \%; en las cabeceras del 14,4\%, y en los centros poblados y rural disperso de $40,0 \%$. En esta misma anualidad, el porcentaje de personas en situación de pobreza multidimensional en los centros poblados y rural disperso fue 2,8 veces el de las cabeceras. Por otra parte, este índice varió en -1,7 \% del 2014 al 2015, es decir, cada vez más va en aumento el índice de pobreza. Una cifra preocupante si además 
se tiene en cuenta que el coeficiente de Gini asciende a un 0,56 , lo cual evidencia que Colombia es uno de los países con mayor desigualdad en el mundo (Dinero, 2016, p. 1).

En vista de tal realidad que vive el país, es necesario que las sociedades y la población contemplen alternativas que apunten al fortalecimiento de la economía en favor de todos, máxime en un escenario de posconflicto en las regiones donde más ha hecho estragos la guerra. El objeto central de esta disquisición tiene como propósito, de acuerdo con el Parlamento Andino, como se cita en Serna y Rodríguez (2015):

Comprender adecuadamente los problemas y proponer soluciones, aprendiendo y utilizando nuevas habilidades y conocimientos con la participación de los investigadores, universidades y la academia en general, pues si se fomenta una política clara y una cultura de emprendimiento solidario, se podrá avanzar hacia un proceso de asociación constructiva e intersectorial y hacia la búsqueda de una paz duradera.

Por esta razón, nótense las ventajas de la construcción de una paz estable y duradera desde las regiones en la nueva era de posacuerdo al considerar desde un análisis académico las ventajas del cooperativismo y la justicia social, lo que permitirá concebir desde un enfoque más claro las razones de centrarse en el fortalecimiento de la trama social, y lo cual se traduce en el logro de una consolidación de experiencias desde la puesta en práctica de los valores y los principios del sector de la economía solidaria. Estos son puntos de referencia en la integración de las regiones, así como el sustrato ejemplarizante que permite contribuir a la reinserción social, la reconciliación y el progreso de aquellos que más lo necesitan. Ahora bien, en el desarrollo de este artículo se revisan las ventajas de la aplicación de la economía solidaria, el cooperativismo y la justicia social desde la economía solidaria para la generación de espacios de paz desde las regiones en el posconflicto, como escenarios fértiles para el progreso colombiano.

\section{Breve abordaje histórico del cooperativismo en Colombia}

En Colombia, la economía solidaria se ha consolidado a partir de 1899 con la creación de las denominadas "sociedades de socorro mutuo" en Manizales, Bogotá y Cúcuta. También con la creación de las "natilleras" en Antioquia, Valle y Cundinamarca, las cuales fueron predecesoras de los fondos de empleados y de algunos precursores de las ideas cooperativistas en Colombia, como es el caso de Rafael Uribe-Uribe, quien con su iniciativa dio paso a la promoción de ayudas sociales a los trabajadores, así como a la creación de diversos estamentos de protección social en Colombia. Fue así que con esta concreción del movimiento cooperativista Uribe-Uribe pronuncia en 1904 su popular discurso "El socialismo de Estado", ${ }^{3}$ en el que plantea el socialismo como medio para resolver los problemas que aquejaban al país, apoyado en el sindicalismo y el corporativismo (Ramírez, Herrera y Londoño, 2016, p. 16). En 1904, se da a la tarea de elaborar un programa de socialismo liberal con intervención del Estado, en el que este asumiera la reivindicación de los derechos de los trabajadores y destaca la creación de sindicatos y cooperativas. Luego, como afirman Ramírez et al. (2016):

En 1931 se da paso a la promulgación de la primera Ley Cooperativa consagrada en la Ley 134 de 1931, en consecuencia, en el año 1932, con el Decreto Ley 874 se procede a dictar medidas para el fomento del Cooperativismo. El Decreto 1339 reglamenta la Ley 134. En 1963 el Gobierno dicta el decreto Ley 1598 que se constituye en el nuevo marco legal del cooperativismo colombiano, con este decreto Ley se inicia el auge del Cooperativismo en Colombia. Es así que mediante el decreto 1587 de 1963 se da la creación de la Superintendencia de Cooperativas, posteriormente por Decreto 1629 del mismo año se le da estructura y funciones a la superintendencia y en 1968 por Decreto 2059 se reglamenta el decreto 1598 de 1963. En 1981, la Ley 24 transforma la superintendencia en Departamento Administrativo Nacional de Cooperativas, en 1988 en diciembre 23 la ley 79 actualiza el régimen legal del cooperativismo y da nueva vida al sector cooperativo. En 1998 mediante la Ley 454 se transforma el Dancoop en

\footnotetext{
3 Propugnaba un "socialismo de Estado" que supuestamente conduciría a un modelo de fuerte intervención estatal. Pero no había tal. Al comenzar su famosa conferencia en el Teatro Municipal de Bogotá en 1904, Uribe-Uribe afirmaba que el "socialismo de Estado" era un mote mal puesto por un diario de la ciudad, "porque propuse que el Estado contribuyera a remediar los males que él mismo ha producido, y que no se habrían presentado sin su arbitraria intervención en las relaciones comerciales de los ciudadanos" (Hernández-Álvarez, 2004).
} 
Departamento Administrativo Nacional de la Economía Solidaria-Dansocial.

Es así que a finales del siglo xix y en las primeras décadas del siglo $\mathrm{xx}$ se expusieron en Colombia las primeras tesis vinculadas a la creación de instituciones especializadas sin ánimo de lucro. Fue el general Rafael Uribe (1904) quien como presidente de la República planteó la idea cooperativa. Luego, el padre Adán Puerto, hacia la década de los veinte, la promueve en el oriente del país con base en el modelo que había visto en Europa en 1931, cuando se expide por primera vez la "Ley de cooperativas", de manera que se aplica en la práctica la influencia de grandes pensadores como Charles Gide y de la Escuela de Nimes, por lo cual desde su nacimiento el cooperativismo colombiano se ajustó a la doctrina y los principios promulgados por la Alianza Cooperativa Internacional (ACI).

Las primeras cooperativas se orientaron al ahorro y el crédito de tipo cerrado, de modo que surgen luego otras de tipo multiactivo, casi todas con funciones de ahorro y crédito. Aunque algunas tesis universitarias tratan aspectos puntuales de la vida y obra de monseñor Puerto-Sánchez, su mejor biografía la constituye un decreto del Gobierno departamental de entonces (1977), y un editorial de Álvaro Gómez-Hurtado en el periódico El Siglo, uno de los escritos que constituyeron la mejor síntesis que se haya efectuado de esta extraordinaria personalidad.

\section{Posconflicto y economía solidaria}

El modelo de economía solidaria ha mostrado ser un importante agente promotor de equidad y desarrollo social. Según Martínez (2008), este promueve la formación del capital social, aporta al desarrollo de la democracia participativa, genera y distribuye ingresos, así como fomenta la democratización de la riqueza y la propiedad. De esta manera, el sector de la economía solidaria constituye un modelo efectivo de desarrollo socioeconómico solidario e incluyente, y debe tener mayor protagonismo en el mejoramiento de la calidad de vida de las personas a partir de formas asociativas en el país. Según el autor, estos elementos deben contribuir a avanzar hacia la difusión de la cultura de la solidaridad y la asociatividad, y el posicionamiento del sector de la economía solidaria como un modelo integral de desarrollo avanzando hacia una Colombia solidaria y en paz. En consecuencia, es preciso mirar un ejemplo claro de cómo la economía solidaria ha impactado en territorios en los que ha predominado el conflicto y la guerra. En este artículo se analiza el cooperativismo en España frente a la posguerra.

\section{El cooperativismo en España frente a la posguerra}

En este sentido, es importante revisar experiencias del movimiento cooperativo en la posguerra en el caso de España, las cuales se resumen en las fases de desarrollo que se describen a continuación.

\section{Las experiencias precedentes al inicio del movimiento cooperativo}

Se describe el comienzo de este movimiento con respecto a los hechos más significativos de finales del xIX relacionados con el cooperativismo, entre los cuales se encuentren, según Morales (2003), la "referencia marginal del cooperativismo en el marco legislativo vigente y la actitud "dividida" del movimiento obrero" (p. 140).

\section{El cooperativismo y la lucha obrera en España}

Comprende desde los comienzos del siglo hasta finalizada la Guerra Civil. En esta etapa se da paso a la primera regulación específica del cooperativismo a nivel estatal y autónomo, se celebran diversos acontecimientos cooperativos y se constituyen las primeras federaciones de cooperativas industriales (Morales, 2003, p. 140).

\section{El cooperativismo industrial en el franquismo: experiencias aisladas de un fenómeno sospechoso}

Morales (2003, p. 140) afirma cómo de forma recíproca la regulación específica y la autónoma tanto a nivel sustantivo como fiscal durante los 40 años de dictadura solo posibilitan experiencias aisladas que, a pesar de todo, consiguen - como es el caso de las cooperativas de Mondragón- perdurar con éxito. 


\section{El cooperativismo de trabajo asociado como alternativa al paro}

Por otra parte, Morales (2003, p. 140). señala: "La tercera fase comienza con la instauración de la democracia - coincidente con un periodo de crisis económica- y la eclosión de este tipo de entidades que entran en crisis precisamente cuando España se incorpora entonces, a la llamada Comunidad Económica Europea".

En el transcurso de sus casi 40 años de dictadura, la sociedad española sufrió constantes transformaciones político-sociales orientadas todas ellas por los principios del nacional-sindicalismo. España después de la Guerra Civil tuvo años difíciles a raíz de la complicación que surgió a consecuencia del bloqueo económico internacional y que acarreó graves repercusiones tanto sociales como económicas y políticas de españoles. Ya a finales de la década de los cincuenta surge el "Plan de Estabilización de 1959", el cual ofrece un nuevo panorama de desarrollo y progreso, a la vez que abre puertas al desarrollo económico futuro.

El marco jurídico de este momento histórico viene dado por la Ley de 1942 que se promulga el 2 de enero y tuvo como fin organizar y disciplinar "en sentido jerárquico y unitario la acción cooperativa". ${ }^{4}$ Como señala Morales (2003, p. 147), "el artículo 30 de la Ley de Cooperación distingue clases de cooperativas, siendo una de ellas las 'cooperativas industriales"'. Esto dio paso a experiencias aisladas pero significativas, si bien el cooperativismo en general, y en específico el de producción, vivió años difíciles por cuenta de la desaparición de muchas cooperativas y la coerción sufrida en la libertad de asociación. A partir de los años cincuenta empieza el resurgir de nuevas organizaciones en multiplicidad de territorios de la geografía española. Probablemente, el hecho más característico fue el nacimiento de la experiencia de Mondragón.

Los orígenes germinales de esta experiencia cooperativa se remontan a la década de los cuarenta, en pleno inicio de la posguerra. Especialmente, en 1941, llega a Mondragón un presbítero, don José

4 "Indicando que las entidades que con anterioridad a la Ley viniesen practicando funciones cooperativas, podrán convalidar su inscripción en el Registro de las mismas, y autorizar su legal funcionamiento como tales cooperativas." (Art .5). Al respecto, véase Gómez (1983, p. 32) y Giménez (1974, pp. 83-84).
María Arizmendiarrieta, ${ }^{5}$ después de haber sido partícipe de la Guerra Civil. En octubre de 1943, se sitúa la piedra angular de este proyecto con la primera realización social a través de la creación de una escuela profesional democráticamente administrada y abierta a todos los jóvenes de la comarca. La Escuela Profesional de Mondragón juega entonces un papel decisivo en el nacimiento y el desarrollo de la experiencia cooperativa, y ejerce una labor educativa sobresaliente tanto en el plano profesional como social (Morales, 2003, p. 148).

Tras una labor de casi quince años prolongados, surge esta escuela de jóvenes que, de forma simultánea, ofrece trabajo de fábrica y estudio, de manera que constituyen las primeras cooperativas de la zona.

En consecuencia, en noviembre de 1956, cinco de estos jóvenes constituyen en Mondragón la primera industria del actual Grupo Cooperativo: "Ulgor18 sCI (Sociedad Cooperativa Industrial)", dedicada en sus inicios a la fabricación de estufas y cocinas de petróleo. Sin embargo, de manera progresiva y a la par del desarrollo de Ulgor18, en el transcurso de los últimos años de la década de los cincuenta empieza el surgimiento progresivo de nuevas cooperativas en conexión con la inicial. Es de destacar que aún con el ánimo de crecimiento estas empezaron a enfrentarse a una serie de problemas comunes relacionados con la imposibilidad en el acceso a recursos financieros que les propiciaran el desarrollo y el fortalecimiento necesario en sus inicios, así como la carencia de previsión social, en razón a la exclusión de las cooperativas del Sistema de la Seguridad Social, además de la escasa coordinación y la asistencia técnica necesaria dada la dimensión del crecimiento de las cooperativas en esa época.

Todas estas dificultades supusieron un contexto de necesidad, por lo que emprendieron una etapa proteccionista a través de los mismos principios ligados al espíritu cooperativo, uno que permitiera la supervivencia y la expansión en un entorno poco propicio del proyecto cooperativo. En reacción a esto, tal como lo señala Morales (2003, p. 148):

5 Sacerdote y activista vasco, José María Arizmendarrieta hizo posible una utopía en la que los propios trabajadores creaban y controlaban empresas, y resultaban ser más productivas que las que seguían el habitual modelo de explotación capitalista. 
Fue la compresión de este aspecto fundamental y la urgencia de los problemas apuntados, lo que determinó la constitución, en 1959, de Caja Laboral Popular, siempre bajo la tutela e incansable impulso de Arizmendiarrieta. La estructura interna inicial de Caja Laboral se correspondía exactamente con las carencias a las que se pretende dar respuesta: una División Bancaria cuya función era, y sigue siéndolo, constituir un puente entre el ahorro popular y la inversión cooperativa, una División Empresarial, para el asesoramiento y promoción de cooperativas, y una División Social, responsable de la gestión y administración del sistema interno propio de seguridad social.

\section{El cooperativismo industrial en la etapa desarrollista más allá de la posguerra}

Durante esta década, se reflexiona y se analizan varios anteproyectos de ley, pues la realidad cooperativa exige un nuevo marco jurídico. Ya que la Ley de 1942 era obsoleta, la organización sindical se dio a la tarea de emprender un diálogo abierto con los cooperativistas y realizar un análisis de diversos aspectos y necesidades del cooperativismo. Esto se llevó a cabo gracias a la celebración de la Asamblea Nacional de Cooperativas del 27 al 30 de noviembre de 1961, la cual contó con la participación de más de 800 asambleístas, 432 representantes directos y 635 intervenciones. Se elaboraron cuatro ejes básicos de estudio: "a) Bases para el futuro ordenamiento jurídico y fiscal de las cooperativas; b) Las cooperativas en el plan de expansión económica; c) Formación cooperativa y d) Crédito agrícola" (Riaza, 1967, pp. 53-56).

Las conclusiones de este primer encuentro constan de 28 bases, y en ellas se concretaron la solicitud de otros asuntos como:

a) Ley única para todas las cooperativas; b) Normas de aplicación general a todas las cooperativas, cualquiera que sea su clase, recogiendo su esencia coincidente, pero derogables para cada clase de cooperativas, si contradicen una norma especial de éstas; c) Normas especiales para cada clase de cooperativas, en cuanto se reputan necesarias, derogando estas normas especiales las de carácter general que sean incompatibles (Giménez, 1974, p. 86).

Aunque el fruto de este encuentro fue la elaboración de un anteproyecto de ley de cooperativas, este no existió porque, "en realidad, la Organización Sindical mantiene bajo control el movimiento cooperativo, no permitiéndole que se autogobierne y se organice federativamente, mediante la adhesión libre" (Riaza, 1967, p. 54).

En 1965, los servicios jurídicos de la Organización Sindical elaboran un Anteproyecto de Ley de Cooperativas que, como se describe en su exposición de motivos, pretende:

Lograr una normalización jurídica que nos sitúe, sin reparo razonable, en el centro de los movimientos cooperativos de cultura afín a la nuestra, y que ofrezca marco holgado a las soluciones que la práctica y desarrollo económico exigen previsiblemente para un futuro no sólo próximo, sino lejano.

Entre las diversas clases de cooperativas, se logró contemplar las "industriales": aquellas que "asocian a trabajadores organizados en empresa para la ejecución de obras, tareas o servicios para terceros". Por primera vez, se dio paso a regular la posibilidad de admitir a personas como "asociados" desde el punto de vista del capital, pero no relacionado con la fuerza de trabajo, y se establecieron límites, contemplados en los estatutos de la sociedad. En enero de 1969, ante el Ministerio de Trabajo se presentó el Anteproyecto de Ley General de Cooperativas, el cual proponía tres tipos básicos de cooperativas según su función fundamental: las relacionadas con la producción, la oferta y la demanda. Ambos anteproyectos no progresaron y quedó en vigor la Ley de Cooperación de 1942.

De acuerdo con las experiencias significativas de la época en este periodo, se dio paso al incrementó de forma desigual y de acuerdo con los años. Es decir, desde 1971 - año en que se estructura el segundo Reglamento de Cooperativas- a 1975 - año en el que fallece Franco y se da fin al franquismo-, la creación de cooperativas aumentó a 681 con un total de 18787 asociados. Si bien es evidente el incremento significativo de cooperativas, las plazas de empleo creadas no fueron suficientes, pero se tuvo la perspectiva de alcanzar mejores condiciones laborales que comprendían la propiedad de los medios de producción (Morales, (2003, p. 152). También en esta época se fortaleció la experiencia de la llamada "intercooperación económica" dentro del grupo de cooperativas asociadas a Caixa Popular 24, como la constitución de la Cooperativa Industrial de Construcción Coinco, en 1975. 
Después de abordar el análisis del caso español en su consolidación como ejemplo claro de construcción de paz y fortalecimiento del cooperativismo, y la economía solidaria como alternativa de desarrollo después de la guerra, es más que necesario revisar el comportamiento del conflicto en Colombia que, si bien tiene características complejas, es propicio para el abordaje de la temática.

\section{Breve abordaje del conflicto armado en Colombia}

Colombia ha sido un país que, en su proceso de avance y desarrollo, le ha tocado enfrentar más de nueve procesos de paz, algunos de los cuales han sido fallidos y han causado un efecto negativo para el crecimiento del país. En este orden de ideas, desde hace ya varios años, la creciente divergencia política y las brechas de desigualdad a causa del conflicto han ocasionado rupturas graves en el intento por fortalecer el tejido social, con el recrudecimiento del ambiente hostil y beligerante, lo que ha propiciado la búsqueda persistente por parte de los gobiernos en la generación de ambientes y espacios de paz con el fin de dar paso al cambio y contribuir a la consecución de los fines y cometidos del Estado, a fin de labrar un futuro próspero y en paz del cual puedan gozar las futuras generaciones.

De esta manera, el desarrollo del conflicto armado presenta etapas diferenciadas en su intensidad y en su geografía, particularidades de los marcos políticos, así como otros procesos de carácter económico y social. Desde este ámbito, es necesario revisar el conflicto desde finales del siglo $\mathrm{xx}$ al siglo XxI. Al respecto, conviene observar la década de los veinte como una etapa crucial, en la cual comienza a tomar cuerpo una fase importante en el desenvolvimiento de la sociedad colombiana, marcada por el ingreso de masivas inversiones norteamericanas, tal como en su momento lo percibieron varios autores, ${ }^{6}$ aunque traía consigo fuertes sucesos como el de la crisis económica de 1929. En contexto, en la década de los veinte y los treinta - desde la perspectiva del desarrollo capitalista de la sociedad

6 Véase al respecto el "Informe conjunto" de la Mesa de conversaciones entre el Gobierno de Colombia y las Fuerzas Armadas Revolucionarias de Colombia, realizado en La Habana en enero del 2014, las páginas 5 y ss. colombiana - se confrontan dos proyectos de sociedad: uno, afianzado en la valoración de la propiedad de la tierra, y otro, confrontado con la propuesta de construcción de una economía nacional apoyada en desarrollos industriales y en una sólida clase media rural (Fajardo, 2014, p. 4).

De acuerdo con Fajardo (2014, p. 5), este último proyecto comenzó a manifestarse con nitidez a mediados de la década de los veinte ${ }^{7}$ a través de dirigentes y pensadores de los dos partidos como fueron Carlos E. Restrepo y Alejandro López, lo que tomaría fuerza en los años siguientes para dar sustancia a los gobiernos liberales y alcanzaría su cumbre entre 1932 y 1936 en los debates sobre las propuestas en torno a la que sería la Ley 200 de 1936. Como señala Fajardo (2014, p. 5), de allí en adelante se inicia el declive con procesos que condujeron al debilitamiento de la orientación renovadora, en lo que se expresa el juego de las fuerzas políticas: lo denominaron la "pausa" del Gobierno del presidente Eduardo Santos, el intento de golpe militar contra el presidente López durante su segundo mandato y la expedición de la Ley 100 de 1944, la cual recuperó formas arcaicas de trabajo en las haciendas.

En adelante, la historia del país pasó del declive de las reformas liberales a un régimen más regresivo en el cual gradualmente se generalizaron las masacres, en particular contra los "gaitanistas" y que denunció Jorge Eliécer Gaitán, la cuales tomaron incluso su vida y abrieron la vía a la guerra civil (Fajardo, 2014, p. 5). La realidad plena del conflicto se vio en su apogeo cuando en ella habría de tomar curso el afianzamiento de un modelo agrario afincado en la gran propiedad. Luego, estimulado por el ingreso de los recursos provenientes del narcotráfico pasa por el propósito de impulsar el mercado de tierras como mecanismo de regulación para la distribución de la tierra sin efecto alguno en ese sentido, y llega hasta la propuesta actual de una política de baldíos en la cual se deja de lado la dotación de tierras para campesinos y se orienta hacia el favorecimiento de grandes inversiones para el desarrollo de empresas agrícolas, iniciativa que creó mediante la Ley 1133 de 2007 el programa "Agro Ingreso Seguro", y que reitera el proyecto de Ley 133 en curso cuando se adelanta este estudio. Todo esto

Véase Kalmanovitz (1985), en especial, la segunda parte, capítulo Iv. También Uribe-Celis (1985), como se citan en Fajardo (2014, p. 5). 
como caldo de cultivo para el conflicto generalizado que ha vivido Colombia (2014, p. 5).

Por consiguiente, un método clave que permite entender la continuidad del conflicto es centrarse en el análisis de la confluencia de los siguientes factores: internos y externos, económicos, políticos e ideológicos (estos dos últimos, sin embargo, vistos desde la misma arista, ya que son los que contribuyeron en su principio a la génesis y permanencia del conflicto). En cuanto a los primeros, se destacan la inamovilidad tanto de la estructura de la propiedad agraria ${ }^{8}$ como la de la participación política, ya que es claro cómo la tierra ha sido uno de los elementos predominantes en el desarrollo del conflicto (Fajardo, 2014, p. 32). En cuanto a los factores externos, ha sido preponderante la aceptación por parte de la dirigencia colombiana de las directrices de la política norteamericana en términos económicos, políticos y militares, las cuales han dado continuidad a las condiciones básicas del régimen de dominación establecido en Colombia con anterioridad a la Segunda Guerra Mundial. ${ }^{9}$ En cuanto al régimen agrario puede observarse cómo, más allá de la confrontación sectaria que efectivamente generó buena parte de los homicidios, destierros, destrucciones de patrimonios y empobrecimiento de la población, crímenes ocurridos entre fines de la década de los cuarenta y la de los sesenta, existen dos procesos que toman fuerza en el marco del conflicto armado en Colombia: de una parte, el afianzamiento y recomposición de la gran propiedad como base de la producción agroexportadora; y de otra, la persecución y el desmantelamiento permanente de las organizaciones agrarias, lo que limita su desarrollo social, técnico y económico e impide el fortalecimiento de sus miembros y sus capacidades como ciudadanos y productores, tareas que deben adelantar en medio de grandes dificultades (Fajardo, 2014, p. 32).

8 En el Informe general del Grupo de Memoria Histórica, se señalan entre los factores del conflicto los siguientes: "la persistencia del problema agrario, y la propagación del narcotráfico; las influencias y presiones del contexto internacional; la fragmentación institucional y territorial del Estado" (Grupo de Memoria Histórica, 2013, p. 111).

9 A propósito de la persistencia del conflicto señala Palacios (2012) la "inhabilidad de los grupos que dirigen la sociedad y manejan el Estado para operar con mayores márgenes de soberanía en el contexto internacional de un lado y del otro, la incapacidad de construir consensos básicos en torno a un régimen político democrático, garante de la convivencia ciudadana, la igualdad jurídica, el amparo de los derechos sociales y el imperio de la ley".
Desde situaciones externas, internas y político-ideológicas el conflicto ha mutado de forma varias veces en el territorio nacional. Una de estas mutaciones, como señala Fajardo (2014), ha tenido como objeto directo de impacto la sociedad colombiana. En razón a su naturaleza, el conflicto armado transmutó a una "guerra social" que, como resultado de su prolongación y su expansión espacial, sus efectos se han hecho sentir prácticamente sobre el conjunto de la población colombiana y sobre su bienestar:

Durante los decenios transcurridos, la suma acumulada de víctimas fatales y desaparecidos puede ascender a más de un millón de personas, más los heridos, mutilados, retenidos y secuestrados y víctimas morales; los desplazamientos, al menos en las últimas tres décadas, han afectado a cerca de $6 \mathrm{mi}$ llones de personas; las pérdidas patrimoniales habría que calcularlas a partir del número de hogares afectados, de los cuales, según la Comisión de Seguimiento a la Política Pública, un $91.3 \%$ abandonó tierras, bienes raíces no rurales, animales, muebles de hogar, etc. y el $52.2 \%$ sufrió el despojo de sus tierras, una superficie estimada entonces en $5.5 \mathrm{mi}$ llones de hectáreas, equivalentes al $10.8 \%$ de la superficie agropecuaria del país. Para ese año (2008) el estimativo global de las pérdidas fue 2.5 billones de pesos por la tierra abandonada y 8.4 billones de pesos por los bienes abandonados, cifra equivalente al $1.96 \%$ de producto interno bruto a precios de 2007 , en tanto que el proceso también se ha traducido en importantes niveles de acumulación de tierras y capitales. (Fajardo, 2014, p. 37)

Desde un enfoque analítico, y en relación con lo económico y lo referente al tema agrario en particular, es viable señalar tres ámbitos de impacto del conflicto social armado individualizados en sí mismos pero que de una $u$ otra forma convergen de manera profunda y son inherentes entre sí: primero, el caos ocasionado por el modelo de desarrollo agrario, consecuente con el del abastecimiento alimentario y, aunado a los dos anteriores, el desplazamiento forzado, más propiamente el éxodo, lo cual genera de forma directa el desempleo y la pobreza generalizada (Fajardo, 2014 p. 37), factores que no pueden ser vistos como efectos colaterales del conflicto, sino directos.

Es entrelas divergencias ocasionadas por el conflicto que la economía solidaria y el cooperativismo 
se convierten en la razón de ser y la alternativa clara de recuperación de los territorios, de manera que traiga consigo el fortalecimiento de la política agraria trazada en los acuerdos de paz y no exista más la limitación en el desarrollo social y económico. Desde las experiencias mostradas por parte de organizaciones solidarias de cara a la construcción de territorios de paz, es claro que se puede fijar un punto de partida para lograr los objetivos para la reducción de las brechas de pobreza y la desigualdad generadas por el conflicto, y así buscar la inclusión de toda la ciudadanía colombiana. De igual forma, se sabe que en estos están también inmersas aquellas personas que han dejado las armas y quieren reincorporarse a la vida civil, de modo que es una gran oportunidad la inclusión que generan las organizaciones solidarias, la cuales han sido un claro ejemplo en la contribución de espacios de paz, desarrollo y avance tanto económico como social. Estas, además, cada vez van más allá de lo anterior y buscan consolidar familias con sentido solidario que en el ejercicio den la espalda al conflicto y a la guerra. Finalmente, se debe sacar provecho a los recursos que suministra hoy la economía solidaria emergente, la cual, a pesar de las condiciones en las que se ha desarrollado, ha demostrado que es posible propiciar un cambio al equilibrar las cargas entre la actual acumulación capitalista y la dominación de clase que dieron como resultado la subversión.

\section{Ventajas de la economía solidaria en tiempos de paz}

Si bien las cooperativas en Colombia han crecido mucho en los últimos años, lo importante de este contexto de la consolidación de esta economía es que se encuentra preparada para lo que trae el fin del conflicto. Todo esto representa una oportunidad. Las cooperativas a nivel mundial han sido muy importantes en contextos de posconflicto y construcción de paz, han contribuido a la disminución de las brechas existentes en lo social y son ejemplo de reconciliación. En épocas de posconflicto, hicieron parte de la integración social al incluir laboralmente a sectores sociales, lo cual demuestra que es así como se puede construir paz hacia el futuro, con cooperación en lo positivo y lucha en pro de la reconciliación.

Ahora bien, en este ámbito complejo de construcción de paz, el sector solidario no se deslinda de lo que en esencia se refiere al concepto que está implícito y a la vez conexo al mismo ejercicio de "construcción permanente de paz" y, por último, su logro definitivo. Un periodo sostenible de posconflicto en este caso tiene un concepto implícito relativo a la construcción de paz, ya que esta trasciende la resolución de conflictos. Cabe resaltar que esta resolución de conflictos se puede dar por medio de negociaciones de paz o victorias militares, ya que no involucra exclusivamente a los actores armados enfrentados, sino que implica también a la sociedad civil, nacional e internacional en la forma de organizaciones no gubernamentales, sector privado, Iglesia y actores internacionales. Por la misma razón, su dimensión temporal es más amplia que la de eventuales negociaciones: se inicia mucho antes del proceso de paz y sus actividades se proyectan hasta bien avanzado el posconflicto. Entonces, es menester señalar que la construcción de paz se da mucho antes que el posconflicto, dado que con la intención de negociación y la voluntad de acabar con la guerra se empieza primigeniamente a emplear la expresión "construcción de paz".

Asimismo, es necesario comprender - como señala Gómez-Restrepo (2003) - que en el marco del conflicto armado:

Vivido en Colombia desde hace ya algunas décadas, se ha comenzado a visualizar lo que se ha llamado el posconflicto, definido éste como la fase que viene después de la firma definitiva de los acuerdos de paz, pero que en algún sentido es deseable construir durante el conflicto, y que supone una recomposición de la sociedad que incluye asuntos como la desmovilización de los actores armados, la seguridad ciudadana, la reinserción y el desarrollo de los acuerdos de paz.

En consecuencia, las perspectivas de las cooperativas en este nuevo escenario social representan un punto positivo en el área rural, lo cual abona el crecimiento del campo y propende a asegurar los niveles y la calidad de vida de los colombianos. El enfoque de género, el enfoque social y la consolidación de nuevas prácticas solidarias ha permitido que de la mano de la comunidad internacional el sector solidario busque medios para preparase y dar respaldo a nuevas ideas, esto es, la creación de cooperativas, nuevas fundaciones, nuevas entidades mutuales que aporten de manera preferencial esperanzas de desarrollo a los jóvenes víctimas del conflicto y a sujetos en condición de reincorporación a la vida civil, 
así como en la acción de vivificación a las mujeres y como acompañamiento en la dirección de cooperativas en Colombia.

En Colombia, el sector de la economía social y solidaria se reconoce como un medio generador de equidad social y económica con capacidad de contribuir a la construcción de un nuevo país. Día a día, lo conforman organizaciones con mayor posibilidad de competir en el mercado, más rentables y cumplidoras de su razón de ser como empresas asociativas.

Esto lo evidencia la Superintendecia de Economia Solidaria (2015) al señalar:

En la participación del sector en un 2,2 \% en el Producto Interno Bruto del país. Así mismo, según cifras reportadas a Supersolidaria a través del capturador de información financiera, el sector solidario tuvo un incremento en el valor de los aportes para la construcción de capital social, que pasó de $\$ 2,4$ billones en el 2003 a \$6,6 billones en el 2013; crecimiento sostenido en la última década de 2,8 millones en el 2003 a 5,8 millones de asociados en el 2013; es decir; un crecimiento del 107 \% y más 18 millones de habitantes que tuvieron la posibilidad de mejorar su calidad de vida al acceder a los diferentes servicios y beneficios que ofrece el sector a los asociados y sus familias. (p. 18)

Para la superintendente, Olga Lucía Londoño-Herrera:

Si bien el sector solidario ha demostrado en los últimos años sus características, principios solidarios y el fortalecimiento; requiere de una atención especial que garantice que el modelo sea sustentable y sostenible en el tiempo, consolidándose como un sector que contribuye al bienestar de los colombianos y que participa en forma activa en el logro de las grandes metas del Gobierno Nacional; entre ellas, el crecimiento de la economía, la reducción de la pobreza y en el desarrollo de la política de inclusión social y financiera. (Superintendecia de Economia Solidaria, 2015, p. 18)

De esta manera, diseñar políticas y estrategias que busquen fomentar la creación de nuevas organizaciones es el objeto central del crecimiento del sector solidario, aunque sin descuidar el compromiso en nuevos escenarios que comprometen el fortalecimiento social de las que ya se han constituido.
A su vez, se debe determinar las falencias con el fin de establecer la definición de políticas que permitan reforzar el compromiso de construcción social.

Una propuesta acertada que conlleva tener estas ventajas es trazar rutas para la recuperación de prácticas asociativas inclusivas. Una propuesta pertinente para esto debe centrarse en un objetivo claro: una vez definidas las zonas específicas de intervención con la firmeza de los acuerdos, se deben recuperar las prácticas asociativas anteriores, en cuanto fuese posible. Al reactivar las prácticas asociativas exitosas y enraizadas en los territorios que más sufrieron el flagelo de la violencia mediante una labor de evaluación y seguimiento constante, así como de aquellas asociaciones y entidades del sector solidario que hayan decaído o fracasado por causa de acciones violentas $\mathrm{u}$ otras circunstancias, y al ser evaluadas en rigor facilitarán considerablemente la tarea de organización socioeconómica.

Por otra parte, y aunado a lo anteriormente propuesto, se debe incentivar a la creación de proyectos asociativos, ya que este punto es clave en el nuevo escenario que plantea Colombia: trazar una línea de ruta en la que en cada área o zona de intervención establecida se busque una necesaria y activa participación de la población víctima, las poblaciones vulneradas y sujetos en proceso de reincorporación o desmovilizados que participaron del conflicto. Esto en razón a que son actores fundamentales, incluso en la conformación de los territorios solidarios, y con miras a las posibles necesidades de atenderlos, a fin de tener un nivel pleno de objetividad en la celebraciones de actividades que propicien la creación de nuevos proyectos asociativos, viables y pertinentes ligados al contexto local y con la intervención de agentes externos de índole internacional, en concordancia con lo que señala Cifras y Conceptos (2015): "Ha quedado demostrado que los proyectos asociativos creados o promovidos por agentes externos, en el caso la Uaeos, han perdurado en la medida en que responden a las necesidades y expectativas reconocidas por la comunidad".

\section{El desarrollo de la economía solidaria enmarcado desde las regiones, los territorios y lo local}

El concepto y la definición básica de desarrollo desde las regiones deriva de tres puntos importantes: 1) el aspecto espacial unido a un tiempo y sector de actividad, en el que confluye la acción humana y 
la inversión de recursos, 2) aquellos actos humanos y económicos ligados al tiempo, al sector y a su ejecución, y 3) la concreción de esquemas tradicionales de planeación económica. De esta forma, estos puntos son inherentes al concepto de "desarrollo desde las regiones" en el sentido de la transmisión de un nivel económico concreto a otro más avanzado en una zona geográfica determinada, sujeta al incremento del bienestar expresados en los indicadores económicos, sociales e institucionales, por lo que su estudio contribuye a la comprensión de los fenómenos socioeconómicos nacionales enfocados en la solución de problemas a nivel regional.

La importancia de este enfoque de desarrollo regional desde la economía solidaria — ambos relacionados- radica en que permite que exista mayor inversión de recursos, lo que garantiza un desarrollo económico y social diferente que tiende a la inclusión, lo cual nos corresponde analizar desde el impacto social (característica propia de este desarrollo). Asimismo, es relevante en la medida en que puede extenderse - de acuerdo con su éxito- a un desarrollo nacional visto desde un sistema propio, de modo que se debe partir de abajo hacia arriba. Con esto se crea un sistema de conformación sistemática que forma parte del desarrollo regional del país.

En consecuencia, a fin de observar un desarrollo regional, es necesario partir de abajo hacia arriba, así como desde una realidad cierta y vivible; por lo tanto, se debe también comprender el desarrollo local, el cual se vincula con un concepto de territorialidad. Así, de acuerdo con Lopera y Posada (2012, p. 126), "se ha entendido tradicionalmente como un proceso de crecimiento económico y cambio estructural que conduce a una mejora del nivel de vida de la población local, creando empleo, renta y riqueza por y para la comunidad local", lo cual deriva, según lo establecen Pérez y Carrillo (2000, p. 48), de "la conjugación de las políticas económicas sectoriales cuyos objetivos están centrados en la mejora de la eficiencia y la productividad".

Por lo tanto, es necesario la participación principal de actores económicos o su influencia en el contexto económico, tales como empresarios, organizaciones empresariales, organizaciones gremiales (e. g. las de trabajadores), las asociaciones, las corporaciones, las cooperativas, las entidades del sector público y otras del resorte financiero. Dado que son estas las que intervienen y están llamadas a intervenir en las políticas territoriales, así como a propiciar el desarrollo económico local, territorial y regional.
Por su parte, Hierro (2000) manifiesta:

El desarrollo local también se ha comprendido como el mayor crecimiento del PIB, sustentado en la producción potencial, acompañado de políticas de crecimiento que se apoyen en la potenciación de los recursos, con niveles de ahorro relacionados con la capacidad de generar proyectos de inversión, la posibilidad del asociacionismo cooperativo, y accesibilidad financiera para proyectar las inversiones. (p. 63)

Hierro (2000) demuestra que este tipo de desarrollo "sería aplicable a cualquier sociedad en la consideración de generar desarrollo local, agregando el reconocimiento de la capacidad empresarial y de su función de generar ahorro como estrategia del desarrollo local a largo plazo" (p. 90).

Por otra parte, Vásquez (2000) asevera: "La capacidad de liderar el propio proceso de desarrollo, unida a la movilización de recursos disponibles en el entorno local, de su potencial de desarrollo, conduce a una forma de desarrollo endógeno" (p. 96). Sin dejar atrás que, desde el aspecto general, los territorios cuentan con elementos económicos, humanos, institucionales y culturales, lo que los hace potencializar el desarrollo al derivarlos a unos procesos de acumulación de capital en localidades y territorios determinados.

Desde esta orbita, es necesario resaltar lo que señala Vásquez (2000): "En función de la organización social del territorio, vinculando una visión de desarrollo duradero en el que juegan un papel estratégico las formas de organización, los sistemas de relaciones y las dinámicas de los aprendizajes" (p. 105). Esto, desde el crecimiento económico.

De este modo, según el desarrollo en regiones concretas, se requiere la garantía del Estado y su presencia - lo garantizarían los acuerdos firmados por el Gobierno nacional y las FARC-EP en La Habana-, debido a que es imperiosamente necesario velar por las libertades constitucionalmente consagradas en la Carta Política y los tratados internacionales como una medida de protección al ciudadano afectado por la violencia y los descuidos del Estado. Esto a fin de propender a que se dé plena garantía del goce de una vida digna, lo que se traduce en la categorización de la constante evolución de la capacidad humana y amplía el radio de opciones y oportunidades para el ejercicio de derechos y el cumplimiento de los deberes a plenitud. 
Es entonces indispensable la economía solidaria. Sus principios y sus valores, todo el edificio axiológico que comprende esta economía: los estamentos sociales con la creación de escenarios de negociación y consenso en pro de la implementación de los recursos de cara a la demanda tecnológica y la globalización.

Parafraseando a Arocena (1995), se puede decir que la experiencia de la globalización supone la consideración de lo local como un inmediato correlato, puesto que no es posible analizar un proceso de desarrollo de esta naturaleza sin referirlo a la sociedad global en que está inscrito. Esto, visto desde la órbita de un sistema, y al mismo tiempo como la afirmación del carácter relativo de la noción de lo local permite reconocer la inscripción de lo global en cada proceso de desarrollo.

Sin embargo, es necesario tener en cuenta que cuando se presentan temas referidos a los asuntos socioeconómicos se producen tensiones, en tanto que la producción de riqueza propicia relaciones y negociaciones entre grupos que, según Arocena (1995, p. 23), se convierten en "el estructurante principal del sistema local de relaciones de poder". De igual manera, se puede observar que la riqueza generada localmente, como condición necesaria, propicia relaciones de propiedad y autoridad en su entorno que determinan el juego de roles sociales. Así, cada actor social ocupa una posición social según su capacidad decisoria sobre el excedente económico de la localidad.

En torno a este paradigma, se juntan los saberes y las prácticas sociales de la sociedad local. La población construye su historia alrededor de unos imaginarios y un sistema de valores que interiorizan individual y colectivamente, lo cual confluye en la identidad colectiva que da sentido a una manera de ser, de estar y de habitar en determinada localidad (Lopera y Posada, 2012).

Arocena (1995) plantea que la sociedad local se define como "una comunidad habitante de un territorio delimitado" (p. 25), según si es portadora de una identidad colectiva expresada en valores y normas interiorizados por sus miembros, y cuando conforma un sistema de relaciones de poder constituido en torno a procesos locales de generación de riqueza.

Todo basado en la idea de un protagonismo destacado de cara al mundo globalizado, apoyado en la teoría de la descentralización de decisiones políticas, lo que da paso al aprovechamiento de recursos y de las ventajas comparativas regionales, en cumplimiento de los "Objetivos del Desarrollo Sostenible", los cuales apuntan a la generación de interrelaciones con el medio ambiente y las tecnologías, la cultura, la socioculturalidad y la sociedad misma, entre otros, a fin de apalancar proyectos productivos locales, territoriales y regionales que deriven en el incentivo de pequeños y medianos proyectos empresariales desde la economía social y solidaria.

Consecuentes con el análisis, no se debe dejar de lado cómo algunas propuestas sujetan los aspectos socioculturales para destacar la definición de la sociedad local, no como la agregación de realidades distantes y fragmentadas, sino como un conjunto de relaciones construidas y desarrolladas en vínculo con la sociedad global, y en tal sentido, en correspondencia con ciertas condiciones de carácter socioeconómico y cultural que le dan la connotación de local (Lopera y Posada, 2012).

De esta manera, los bienes y servicios que sirven a la satisfacción de las necesidades no solo requirieron un proceso de producción social, sino también un conjunto de participantes y niveles de actuación que se concretan en los bienes sociales. Es esto lo que se busca vislumbrar con este análisis, en el entendido de que esto evidencia de manera real a través de las experiencias de las comunidades organizadas una posibilidad multibenéfica de sobrevivencia, así como en los servicios y los programas que ofrecen las organizaciones. Se debe aclarar que el eje de discusión será la manera coherente de respuesta lógica de la economía solidaria, y esta se concreta de forma descendente desde la región, desde el territorio y en lo local, porque se reconoce que el desarrollo se realiza en los espacios locales con trascendencia a los territoriales, y con impacto a lo regional, lo que conforma una acción hacia lo nacional. Así se da el resultado del accionar constante de sujetos que interactúan de manera individual como primera medida, y luego colectiva y socialmente, a través de propuestas articuladas con el saber y la experiencia significativa en pro de la construcción de una sociedad incluyente por medio de "territorios solidarios".

Un ejemplo claro de la creación de territorios solidarios es el caso de éxito de la "Integración desde la economía solidaria para la generación de espacio de paz desde las regiones" en San Gil, el territorio solidario del sur de Santander estrechamente ligado a los procesos educativos - como es tradición en esta región-, algunos de estos impulsados por organizaciones a cargo de organizaciones y 
cooperativas que han fundamentado su desarrollo a través de procesos formativos en economía solidaria, ruedas de negocio y pasantías, y se han ideado diversas rutas que muestran y enseñan las características cooperativas, los procesos agroindustriales, los medios de comunicación comunitarios y los servicios financieros del territorio. Todo esto ligado al sector turístico, ya que esta zona, además de ser rica en solidaridad, está colmada de detalles históricos, municipios coloniales, músicos y tiples, amplia gastronomía y bellos paisajes naturales. Este es uno de los procesos territoriales y solidarios que debe ser visto como punto de referencia y experiencia para ser replicado en otras zonas del país en las que se ha acentuado el conflicto. Este fortalecimiento ha dado frutos gracias a la investigación y el compromiso constante, direccionados a una metodología de la construcción del territorio solidario.

Finalmente, lo más importante de esta experiencia significativa es que, según Organizaciones Solidarias (2011):

El sistema de economía solidaria de la región cuenta con un sistema de articulación de las empresas de economía solidaria, sobresalen las organizaciones gremiales de los campesinos y productores rurales: Fedetabaco, el común, los paneleros, el gremio del turismo, los bocadilleros, los fiqueros y los fruticultores. Por su parte las organizaciones cooperativas cuentan con Confecoop y Coopcentral. Las 33 emisoras comunitarias están articuladas en Resander. (p. 10)

\section{Conclusiones}

Es consecuente que la economía solidaria surja en contraposición a las desigualdades sociales que se dieron en el contexto de las revoluciones del siglo XVIII. Hoy, en pleno siglo XXI, este movimiento de fortalecimiento social sigue proponiendo nuevos escenarios de desarrollo para los más necesitados, siempre en búsqueda de obtención de una mejor distribución de los ingresos que, al propiciar el fortalecimiento de la calidad de vida de los asociados en el caso de las cooperativas, y de los demás beneficiarios en el caso de otras entidades pertenecientes a la economía solidaria- permite la justicia social, con el pleno propósito de dignificar la labor del campesino, el trabajador, el obrero y el empleado, y crea así un modelo con principios de justicia y equidad. Estos dos últimos son los axiomas del cooperativismo, situación que debe ser prevalente en estos nuevos escenarios que plantea el país, pues la visión de la economía abierta que plantea la economía solidaria va en contraposición a lo que hoy podemos llamar una "irregular manifestación de una economía de capital voraz que no distingue de raza y género". Por lo tanto, la consolidación de esta misma economía solidaria se direcciona cada vez más en un desarrollo flexible del mercado, lo que la dispone al cambio y siempre a aportar al desarrollo, gracias a la implementación de estrategias que permiten y permitirán - de cara a los cambiosenfrentar el desafío propuesto que trae consigo el posconflicto.

En el contexto actual, para la consolidación del proceso de paz en Colombia, dados sus principios, alcances y posibilidades en torno a la justicia, la libertad, la equidad y la solidaridad, la economía solidaria se constituye en un escenario apropiado para la implantación del posconflicto pues involucra, especialmente, la solidaridad, la unión y la equidad como principios que permiten el desarrollo sostenible de las regiones y la resolución de problemas comunes (como los que ha vivido la sociedad colombiana hace varias décadas, caracterizados por la violencia y el enfrentamiento). Ahora que se diseña un camino hacia la paz, en definitiva, la solidaridad puede ser un motor generador de espacios de entendimiento y cooperación que aporte en la solución definitiva para alcanzar una paz duradera. La economía solidaria debe verse como un modelo que propone ventajas para el mejoramiento de la calidad de vida de sus asociados, de las regiones y los pueblos, siempre y cuando se construya sobre la base en la aplicación rigurosa de los principios generales del cooperativismo.

La evolución de la economía solidaria frente a la creación de empresas de trabajo asociado marca una pauta en el crecimiento a pesar de las diversas etapas diferenciadas por las condiciones económicas del territorio, por lo cual es indispensable la articulación de intereses representativos y la respuesta diversa del Estado y los gobiernos con la generación de una concepción, más o menos generalizada, de los obstáculos que impiden su desarrollo como fórmula empresarial desde lo solidario frente al posconflicto. Como se pudo ver en el caso de España, cada una de las etapas, según señala Morales (2003, p. 168), se fraguaron con un arquetipo específico de empresa con enfoque social de trabajo asociado acorde con estas circunstancias socioeconómicas 
del contexto, a partir de modelos empresariales defensivos y periféricos originados por crisis sectoriales en el ámbito industrial. En el caso de Colombia, es más viable la aplicación de fórmulas de colaboración público-privada en el sector servicios, así como iniciativas innovadoras para la generación de empleo, inclusión y construcción de paz.

Experiencias utópicas como instrumento de lucha obrera a comienzos de siglo, experiencias aisladas, pero altamente significativas que se desarrollaron en un marco adverso en la época franquista, y la expansión del fenómeno por todo el territorio español constituyen el resultado visible de un fenómeno singular y algo ectópico desde los valores individualistas y competitivos que se propugnan y generalizan en una economía de mercado.

En efecto, entender lo necesario y lo fundamental de la microempresa con enfoque familiar es pertinente, ya que puede favorecer el cumplimiento de los principios básicos de la economía social y solidaria para que, supeditados al funcionamiento de dichos principios, se dé una respuesta positiva ante la urgencia de respuestas que exige un mercado en proporción a la aplicación de la gama axiológica inherente a la misma economía en cuestión.

Conviene, por tanto, ser conscientes, así como tener credibilidad y capacidad para transformar las relaciones económicas y crear relaciones económicas de mercado, de manera que sea este el paso al fortalecimiento de las entidades existentes. Es de suma importancia contribuir a los indicadores cualitativos de desarrollo considerados efectivos en intercooperación social y económica, ya que estos generan una cultura de solidaridad imprescindible para el éxito de las políticas de distribución equitativa de rentas y de crecimiento económico.

Además, se concluye sobre lo importante de sensibilizar más a las instituciones públicas y privadas de estas tendencias a fin de que reconozcan a los diversos interlocutores representativos de las empresas de trabajo asociado al margen de las situaciones sociales y los contextos reales del pueblo colombiano, como referentes de una realidad social cada vez más amplia e inserta en el ámbito de la generación de espacios con enfoque solidario. Si bien existirán dificultades para el cooperativismo rural en el posconflicto, el compromiso es múltiple por parte de la sociedad y los dirigentes, así como ocurrió en el caso de Mondragón. Si bien la no desmovilización del ELN y las bandas criminales representaría una amenaza latente, lo beneficioso seria que con la conformación y constitución de nuevas iniciativas relacionadas y pertenecientes al sector solidario se propicie la participación y la inclusión de exguerrilleros, exmilitares y personas de la sociedad (desplazados, víctimas del conflicto, campesinos, organizaciones sociales y demás) en el propósito de generar una concreta reconciliación.

\section{Referencias}

Arocena, J. (1995). El desarrollo local: un desafío contemporáneo. Montevideo: Taurus.

Boutros, G. (1992, enero 31). Naciones Unidas. Recuperado de http://www.un.org/en/sc/repertoire/89-

Chetail, V. (2009). Post-conflict peacebuilding: A lexicon. Nueva York: Oxford University Press.

Cifras y Conceptos. (2015). Programa: estudio de percepciones de incidencia de Uaeos en el desarrollo organizacional de entidades creadas y fortalecidas. Bogotá: C\&C Action Marketin Ltda.

Departamento Nacional de Estadísticas-DANE. (2016). Boletín técnico pobreza monetaria y multidimensional en Colombia 2015. Bogotá: Imprenta Nacional.

Dinero. (2016, febrero 3). El 7,9 \% de colombianos vivieron en pobreza extrema en el 2015. Revista Dinero, 2.

Fajardo, M. D. (2014, noviembre 15). Comisión histórica del conflicto y sus víctimas. Centro de Memoria Histórica. Recuperado de https://www.centrodememoriahistorica.gov.co/descargas/comisionPaz2015/ FajardoDario.pdf.

Galtung, J. (1975). Three approaches to peace: Peacekeeping, peacemaking and peacebuilding. En Peace, war and defence. Essays in peace research ( $2^{\mathrm{a}} \mathrm{ed}$.). Copenhague: Christian Heljers.

Gómez, G. (1983). La cooperativa de trabajo. Barcelona: CEAC.

Gómez-Restrepo, C. I. (2003, enero 22). El posconflicto en Colombia. Imbiomed.com. Recuperado de http:// www.imbiomed.com/1/1/ articulos.php?method=showDetail\&id_revista $=115 \&$ id_seccion $=1782 \& i d$ ejemplar $=2558 \&$ id_articulo $=24831$.

Giménez, T. (1974). El movimiento cooperativo en España. En J. Sanz-Jarque, Cooperacion (pp. 83-84). Valencia: Universidad Politécnica de Valencia.

Grupo de Memoria Histórica. (2013). ¡Basta ya! Colombia: Memorias de guerra y dignidad. Bogotá: Imprenta Nacional.

Hernández-Álvarez, M. (2004). Fragmentación de la salud en Colombia y Argentina: una comparación sociopolítica 1880-1950. Bogotá: Universidad Nacional de Colombia. 
Hierro, L. A. (2000). El desarrollo local en el marco de la economía. En B. Peréz y B. Carrillo (Coords.), Desarrollo local: manual de uso (pp. 59-92). Madrid. España: Esic Famp.

Kalmanovitz, S. (1985). Economía y nación. Una breve historia de Colombia. Bogotá: Siglo XXI.

Lopera, L. D. y Posada, G. J. (2012). Contribuciones de la economía solidaria al desarrollo local: el caso del Altiplano Norte, departamento de Antioquia. Semestre Económico, 12(23), 119-132.

Martínez, J. (2008). Políticas públicas y economía solidaria en Colombia. II Encuentro Nacional de Educación. Evento realizado el 6 de agosto en Bogotá, Colombia.

Morales, A. C. (2003). La democracia industrial en España: orígenes y desarrollo de las empresas de trabajo asociado en el siglo xx. Revista de Economía Pública, Social y Cooperativa ,4, 137-173.

Organizaciones Solidarias. (2011, abril 22). Departamento administrativo para las organizaciones solidarias. Orgsolidarias.gov.co. Recuperado de http://www. orgsolidarias.gov.co/sites/default/files/pagina-basica/pdf/Revista\%20Solidaria\%20N\%2021.pdf.

Palacios, M. (2012, agosto 30). Daños colombianos. El Tiempo. Recuperado de https://m.eltiempo.com/ archivo/documento/CMS-12179575.

Peréz, B. y Carrillo, B. (2000). El modelo teórico del desarrollo local. En B. Peréz y B. Carrillo (Coords.), Desarrollo local: manual de uso (pp. 39-57). Madrid: Esic Famp.
Ramírez, L. F., Herrera, J. D. y Londoño, L. F. (2016). El cooperativismo y la economía solidaria: génesis e historia. Cooperativismo y Desarrollo, 24(109). doi: https://doi.org/10.16925/co.v24i109.1507.

Rettberg, A. (2003). Diseñar el futuro: una revisión de los dilemas de la construcción de paz para el postconflicto. Revista de Estudios Sociales, Facultad de Ciencias Sociales Universiadad de los Andes, 15-28.

Rettberg, A. (2012). Construcción de paz en Colombia: contexto y balance. En Construcción de paz en Colombia. Revista de Estudios Sociales, Facultad de Ciencias Sociales Universiadad de los Andes, 59-34.

Riaza, J. M. (1967). Cooperativas de producción, experiencias y futuro. Bilbao: Ediciones Deusto.

Serna, H. y Rodríguez, M. S. (2015). El sector solidario como alternativa para el desarrollo social e inclusivo en el posconflicto colombiano. Cooperativismo \& Desarrollo, 23(107), 37-48.

Superintendencia de Economía Solidaria. (2015). Sector solidario, comprometido con la superación de la pobreza extrema. Revista Enlace Solidario, (6), 1-36.

Universidad del Rosario. (2014, enero 12). Experimentos sobre reconciliación política en Colombia. Urosario. edu.co. Recuperado de: http://www.urosario.edu.co/ jurisprudencia/jurisprudencia-reconciliacion/ur/ Postconflicto/

Uribe-Celis, C. (1985). Los años veinte en Colombia: ideología y cultura. Bogotá: Ediciones Aurora. 